\title{
New Theoretical Horizons Regarding the Nature of Consciousness
}

\author{
Marjorie Woollacott ${ }^{1}$ \\ University of Oregon
}

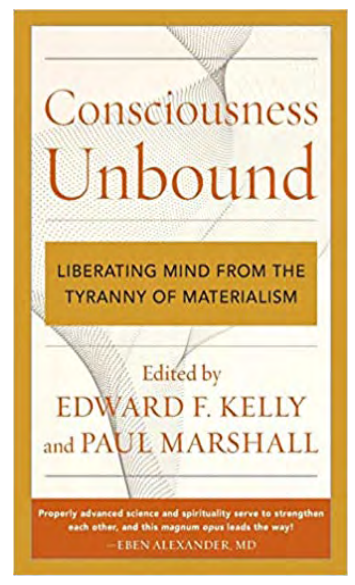

A Review of

CONSCIOUSNESS UNBOUND: LIBERATING MIND FROM THE TYRANNY OF MATERIALISM, edited by Edward F. Kelly and Paul Marshall. Rowman \& Littlefield, 2021. Pp. xiii + 515 (hardcover). \$60.00. ISBN 978-1-5381-394-24

Consciousness Unbound provides a thoughtful and thorough examination of modern theories about the non-material nature of the universe that are alternatives to the reductive nature of scientific materialism. This volume is the third major output of a series of Esalen Institute Research seminars discussing empirical evidence regarding the question of postmortem survival. The creation of the three volumes was spearheaded by Edward Kelly of the University of Virginia, in collaboration with other editors, and Kelly brings some of the best minds in this field together to discuss issues that makes the volumes compelling. The first two volumes, Irreducible Mind and Beyond Physicalism (Kelly et al., 2007, 2015), provide helpful additional resources that lay

1 Address correspondence to: Marjorie Woollacott, Ph. D., Professor Emeritus, Institute of Neuroscience, 25 Siesta Lane, Sedona, AZ 86351, USA, mwool@uoregon.edu 
important groundwork for this volume, as well as providing research from neuroscience and philosophy that support the proposition that consciousness is a fundamental aspect of nature.

As I read through Consciousness Unbound, I was fully engaged by how each contributor systematically unfolded their findings and insights, receiving a clear explanation of the roots and scientific bases of metaphysical theories such as idealism and dual-aspect monism, as well as their relevance in understanding the nature of the universe. This volume starts with the statement that "most contemporary psychologists, neuroscientists, and philosophers of mind subscribe explicitly or implicitly to some version of 'physicalism,' the austere philosophical descendant of the 'materialism of previous centuries'" (Kelly, p. 1). This view holds that all aspects of mind and consciousness are produced by the brain and depend on it for their existence. Within this view all humans, other animals, and plants are seen as simply extremely complex biological machines. The contributors to this volume take a very different view.

The volume is divided into three parts. Part I focuses on phenomena considered challenging for theoreticians of consciousness, including chapters on Near-Death Experiences (NDEs) (by Greyson), Cases of the Reincarnation Type (by Tucker), and Precognition (by Rosenberg). These are difficult because they belong to a category of anomalous phenomena that challenge our understanding of what happens after death (NEDs and reincarnation), and of the nature of time, causality, and freewill (precognition). Part II introduces new theoretical horizons and includes five frameworks or metaphysical perspectives on the fundamental nature of consciousness that oppose the materialist perspective. These include chapters on C.G. Jung's holism (by Main), reflexive monism (by Velmans), A neo-Hegelian theory of mystical experience (by Magee), analytic idealism (by Kastrup), and a new quantum physics approach to the primacy of consciousness (by Faggin). Finally, Part III focuses on further horizons in science, the humanities and philosophy, with chapters on Expanding a Science of Consciousness (by Presti), The Future of the Humanities (by Kripal), Mind Beyond Brain, focusing on the mystical landscape (by Marshall) and an Epilogue, looking at an emerging vision of consciousness (by Kelly).

I have selected two chapters from Part II to highlight, the first, by Bernardo Kastrup, exploring analytic idealism, and the second, by Federico Faggin, exploring a new conceptual framework he derives from quantum physics, which he calls the CIP Framework. I chose them because they contain strong counter arguments to the physicalist perspective, with clear proposals about a view in which consciousness is seen as fundamental. 
The chapter by Bernardo Kastrup is "Analytic Idealism and Psi: How a more Tenable Metaphysics Neutralizes a Physicalist Taboo." He begins it discussing what he calls the "cracks" now beginning to appear in the physicalist armor in his view, and then offers a more plausible metaphysics, "analytic idealism," that posits spatially unbound, universal phenomenal consciousness to be nature's fundamental ground, with all natural phenomena reducible to consciousness. He thus proposes that all living beings (including all forms of plants and animals) have a conscious inner life, and in addition, there is a consciousness beyond all these individual minds, which is universal and consists of the representation of transpersonal experiential states. This mental activity presents itself to us as the inanimate universe.

One of his innovative ways of explaining the primacy of consciousness is through patterns of observation within psychiatry and neuroscience that are, in fact, consistent with idealism. He proposes that certain forms of psychiatric dissociation such as dissociative identity disorder (DID) give us a strong analogy for explaining the emergence of individual minds within creation. Kastrup proposes that all living beings are simply dissociated mental complexes or, in psychological terms, alters, of a unitary universal mind. And he uses the analogy of the experience of someone with a DID having multiple separate centers of awareness. This creates a situation in which each living being and the universe as a whole is a conscious entity, each with their own first-person experience. But when we look out from that first-person perspective at others, we perceive them as other, as matter within a material universe. In fact, Kastrup proposes that all matter is simply what consciousness looks like from the view across the dissociative boundary.

Kastrup goes on to explain how the barriers of the universal DID can begin to become porous and therefore allow an expansion of consciousness. He notes that if analytic idealism is accurate, some forms of brain impairment should disrupt the dissociative boundary and be correlated with an expansion of consciousness. In fact, there are many reports in the medical literature of this phenomenon, notably the near-death experience (NDE) in which, under cardiac arrest and flat EEG, individuals perceive accurately events happening during resuscitation (Van Lommel et al., 2001) and psychedelic experiences, in which "the magnitude of the decrease in brain activity predicted the intensity of the subjective effects" (Carhart-Harris et al., 2012, p. 2138). Although I am a neuroscientist with a career working in neurological rehabilitation, and thus could also argue from the materialist perspective that there are many cases in which brain impairments from lesions such as a stroke severely impair sensory, motor, and cognitive function, I believe that Kastrup raises examples of interesting research countering this point of view. I have examined the literature that Kastrup refer- 
ences on this point and believe that the scientific literature gives evidence to support this point (Woollacott \& Shumway-Cook, 2020).

Finally, Kastrup states that, according to analytic idealism, the living body is simply the representation, the extrinsic experience of a dissociative process of universal consciousness; thus the end of life is simply the end of dissociation, as the previously dissociated mind is reabsorbed into universal consciousness, with one's core subjectivity untouched. What would survive is the core sense of "I-ness," the one eye that looks out from all creatures.

Kastrup's proposals have many points of resonance with the perennial philosophies of the world, which are based on the mystical experiences of individuals who undergo states of unitive awareness (Nisargadatta, 2009; Marshall, 2015; see also Kripal, this volume). For example, a common phrase in many mystical traditions is "I am That," coming from the experience of mystics of having their individual identity dissolve into a vast consciousness, often described as infinite light and love. It is also in accordance with the experiences of some persons during NDEs, in which they merge with a vast consciousness, described as light and love, suggesting that this could be a state experienced at death of the physical body (Greyson, 2021).

What are the limitations of this view? As Kastrup himself says, "ultimately it all comes down to evidence, not theory." He states that "If there are strong enough indications that personal agency does persist-in some form-after bodily death, then theory must follow the evidence, not the other way around." (Kastrup, p. 277).

The second chapter I want to review in more detail is "Consciousness Comes First," by the physicist and computer scientist Federico Faggin. He begins his chapter describing a key aspect in the development of his theory: his story of how he came to begin to work on a new theory of consciousness. One night, as he was in the process of struggling to create a conscious computer, and in the midst of an existential crisis regarding the meaning of his life, he had a profound experience. In it he felt a rush of energy that felt like love emerging from his chest, a feeling beyond any idea he had of what love is. Simultaneously he perceived this energy as a beam of shimmering light. It then exploded and expanded to embrace the entire universe. He said that, in that moment, he knew, as a deep inner understanding, that this was the substance from which the universe was made, that this light had created the universe out of itself. He then became aware that he was also that light. This was the key moment that impelled him to move forward to find a theory of consciousness that would solve the problems of materialism he noted earlier in his career as a computer scientist. He said that for the first time he was aware of being both a part of the world and an observ- 
er of the world. And he saw that the world's essence, light/love, knows itself through self-reflection. He said it was a direct knowing from the inside, stronger than that from human logic. He described experiencing himself as both a particle, and a wave using the analogy of quantum physics: The particle aspect was his ability to experience his own identity, while he at the same time experienced being the entire world, the wave aspect. He was the One observing knowing itself, as one point of view of the One.

It was this experience that impelled him to withdraw from his other activities and focus on developing a model of reality based on the assumption that consciousness is fundamental.

His model is based on quantum field theory (QFT), which he states is "the most accurate current model of reality we currently have (Faggin, p. 287), with the addition of proposing that consciousness already existed before the creation of the universe. Though there are different interpretations of QFT, Faggin takes the position that the probabilistic aspect of QFT makes it compatible with free will. He also states that QFT proposes that the universe is an indivisible whole, in which forms keep emerging, changing, and disappearing. He goes on to propose that consciousness and freewill are holistic properties of each quantum field, thus allowing the outer physical states of a field to be changed from within. This is his fundamental hypothesis: that reality is made of conscious entities if we grant to the quantum fields the capacity to be conscious and to act with free will.

As he continues the explanation of his theory, Faggin's words also begin to sound like those of the authors of the perennial wisdom traditions of the past centuries, as his view of quantum physics merges with that of the experience of mystics. He notes that in order to manifest a universe like ours, the One, who is the totality of what potentially and actually exists, must be dynamic, holistic, and have both interiority and exteriority. He says these properties are what are missing from our current models of physics, and they express the capacity and desire of the One to experience and know itself.

In reading these words of Faggin's I was reminded of a quote from an ancient text (Abhinavagupta, quoted in Wallis, 2012, p. 63) that unfolds a similar theme, "The Self is an embodiment of the Light of Consciousness... As an independent play of intense joy, the Divine conceals its own true nature [by manifesting plurality], and may also choose to reveal its fullness once again at any time." Thus, for Faggin and for the $10^{\text {th }} \mathrm{C}$. author of this text, Abhinavagupta, the One is seen as embodying the light of awareness and concealing its own true nature (infinite awareness) as it creates plurality (that is all of the individual conscious selves of the universe) out of its own joy, to experience and know its own self. Faggin ends his chapter by applying this theory 
to many psi phenomena, including reincarnation, telepathy, and out-of-body experiences.

Like Kastrup, Faggin includes in his chapter a proposal about what happens when we die. He states that when the body dies we lose the ability to observe the physical world from the point of view of the body, but keep the connection with the larger Self, so that we observe the world from this perspective, revealing our true nature. Thus, postmortem survival is associated with this theoretical framework.

One of the striking features of many of the chapters in this volume is that their exploration of consciousness is the result of a first-person experience regarding the nature of reality and of the unitary nature of an expansive consciousness. As a scientist working in neurological rehabilitation, I understand that not all first-person experiences are veridical, and some may in fact be hallucinations. Thus, a materialist scientist might dismiss the anomalous experiences described by these authors as simply hallucinations, as these experiences do not coincide with the reductive theory of reality. Therefore, any theory based on an interior experience could be judged as fallacious. However, the experiences described here offer interesting insights into possible theories of consciousness and thus they might inform new research. Jeffrey Kripal, the author of a later chapter in this volume, notes in his book The Flip (2019), that vast numbers of materialist scientists have had experiences akin to Faggin's, where they have an epiphany of mind, in which they have a reversal of perspective from the outside of things to the inside of things, and from the object to the subject. And he notes that they do this without giving up an iota of their remarkable scientific and medical knowledge. Thus, Kripal argues, the materialist framework is not wrong, it simply needs to be expanded to include mind as fundamental to the cosmos (Kripal, 2019). I agree.

What are the strengths and weaknesses of this volume? If I put my materialist/ physicalist hat on (which I have worn during much of my career as a rehabilitation neuroscientist), I would have asked that some additional chapters be included in the volume from proponents of the physicalist perspective, with authors giving counter evidence that all phenomena discussed in the volume can be explained from what they might call a naturalist perspective. This could be considered a weakness. However, this argument could be softened and countered by the editors with the point that their authors have included in their chapters arguments presented from the physicalist point of view, and presented reasons that they believe these are untenable (see, e.g., chapters by Greyson [section on proposed physiological models for NDEs] and Kastrup [section on the insoluble problems of mainstream physicalism], as just two examples. 
In conclusion, though I have not given detailed accounts of the other chapters in this volume, let me simply say that they were all highly engaging and, as a whole, give very convincing theoretical frameworks and scientific evidence supporting the idea of the fundamental nature of consciousness and its survival after the body dies. If read with open-mindedness and curiosity these chapters could have an incredible impact on our understanding of the nature of consciousness. Each of these theories offers answers to conundrums that materialism cannot explain, such as the nature of near-death experiences, mystical experiences, cases suggestive of reincarnation, and psi phenomena such as precognition. I highly recommend this book to all readers who see the real limitations of materialism/physicalism, but who also want to know more about the scientific evidence and practical benefits of alternative non-material worldviews regarding the nature of reality.

\section{References}

Carhart-Harris, R. L., Erritzoe, D., Williams, T., Stone, J. M., Reed, L. J., Colasanti, A., ... Nutt, D. J. (2012). Neural correlates of the psychedelic state as determined by fMRI studies with psilocybin. Proceedings of the National Academy of Sciences, 109(6), 2138-2143. Doi: 10.1073/ pnas. 1119598109

Greyson, B. (2021). After. A doctor explores what near-death experiences reveal about life and beyond. Saint Martin's Press.

Kelly, E. F. (2021). Introduction. In E. F. Kelly \& P. Marshall (Eds.). Consciousness Unbound: Liberating Mind from the Tyranny of Materialism, Rowman \& Littlefield.

Kelly, E. F., Kelly, E. W., Crabtree, A., Gauld, A., Grosso, M., \& Greyson, B. (2007). Irreducible mind: Toward a psychology for the 2lst century. Rowman \& Littlefield.

Kelly, E.F., Crabtree, A., \& Marshall, P. (Eds.). (2015). Beyond physicalism: Toward reconciliation of science and spirituality. Rowman \& Littlefield.

Kripal, J. (2019). The flip: Epiphanies of mind and the future of knowledge. Bellevue Literary Press. Marshall, P. (2015). Mystical experiences as windows on reality. In E. F. Kelly, A. Crabtree, \& P. Marshall (Eds.). Beyond physicalism: Toward reconciliation of science and spirituality (pp. 39-76). Rowman \& Littlefield.

Nisargadatta, M. S. (2009). I Am That (M. Frydman, Trans.; S.S. Dikshit, Ed.) The Acorn Press.

Van Lommel, P., van Wees, R., Meyers, V., \& Elfferich, I. (2001). Near-death experience in survivors of cardiac arrest. Lancet, 358(9298), 2039-2045.

Wallis, C. (2012). Tantra illuminated. Mattamayura Press.

Woollacott, M., \& Shumway-Cook, A. (2020). The mystical experience and its neural correlates. Journal of Near-death Studies, 38(1), 3-25. 